\title{
Trends of Serious Games Research from 2007 to 2017: A Bibliometric Analysis
}

\author{
Serdar Çiftci \\ Correspondence: Sedar Çiftci, Adnan Menderes Universitesi, Egitim Fakultesi, Aydin, Turkey.
}

Received: December 3, 2017

Accepted: January 9, 2017 Online Published: January 20, 2018

doi:10.11114/jets.v6i2.2840

URL: https://doi.org/10.11114/jets.v6i2.2840

\begin{abstract}
This study examines the tendencies of studies carried out using text mining methods under the title of "serious game". A query was run for the "serious game" keyword in the Web of Science search engine to acquire the data. The study included publications that were scanned in the SCI-EXPANDED, SSCI and A\&HCI indices between 2007-2017. Information could be acquired for a total of 1431 publications. Firstly, the obtained data were cleansed of erroneous and unnecessary information by way of a pre-process. According to the data set cleansed of errors, the total number of common citations was 12701 , number of citations per publication was 8.88 , whereas h-index was determined as 51 . Analyses were carried out by examining all "serious games" publications on the basis of: year, author, journal/symposium name, keywords, research areas and common citation parameters. According to the results, there was a continuous increase over time in the number of publications and citations. Even though "serious games" is a topic that is frequently studied in the field of education technology studies in fields such as psychology, health care sciences, environmental sciences, ecology, public environmental occupational health, rehabilitation, business economics and psychiatry shows that "serious game" is also a popular topic for studies in different disciplines.
\end{abstract}

Keywords: serious game, bibliometric, science mapping, text mining, trend analysis

\section{Introduction}

The use of games in education dates back to old times. Digital games have gained an important place for themselves after electronic devices and the internet found an effective place in our lives. The fact that gamers (individuals who play games) spend more than 10 thousand hours playing games until the age of 21 , which is equivalent to the time spent for education from primary school to secondary school, is an indication regarding the importance of digital games in the lives of individuals (McGonigal, 2011). Computer games have been evaluated as devices that can be used for education ever since they have been designed (Egenfeldt-Nielsen, 2011). Gamers face situations in which they have to make short and long term decisions or form problem solving strategies for the complex tasks or nested sub-tasks (Johnson, 2006). Computer games may provide a strong learning tool by providing means for motivating individuals and increasing interaction in addition to the opportunity for "learning by doing" (Kirriemuir \& McFarlane, 2004). McFarlane, Sparrowhawk and Heald (2002) put forth that playing games is related to decision making, design, strategy, cooperation and problem solving skills. In addition, it is also thought that playing computer games may develop cognitive skills (Robertson \& Howells, 2008) while providing opportunities for developing decision making, design, strategy, cooperation and problem solving skills (Ebner \& Holzinger, 2007; McFarlane et.al., 2002).

When the subject of education is considered, games are expressed in the literature with expressions such as "serious games, computer games, video games, learning games, education games and simulation games". Some definitions overlap with others or may encompass each other. The terms serious games (SG) and game based learning (GBL) are sometimes used synonymously (Corti, 2006). In his book entitled "Serious Games", Clark (1970) discussed the impact of the results obtained from a study on how war games and simulations affect the education of individuals. Based on this he has defined serious games as those with objectives focused not only on entertainment but also on education.

Various definitions have been made for SG (e.g.: Hakulinen, 2011; Stokes, 2012; Taylor, Harlow, \& Forret, 2010). Those who produce such definitions generally agree on the "pedagogy to infuse instruction into the game play experience" expression by Abt in 1970 (Greitzer, Kuchar, \& Huston, 2007). In addition, many authors in the literature are of the opinion that "learning games" are valuable with regard to motivation and learning gains (Connolly, Boyle, MacArthur, Hainey, \& Boyle, 2012; Lee \& Peng, 2006). SG has been developed for the broader purposes of training and behavior change in 
business, industry, marketing, healthcare and government as well as in education (Sawyer \& Smith, 2008).

Many literature review studies have been carried out. One of those on SG which stands out is the "systematic literature review" study by Connolly, Boyle, MacArthur, Hainey and Boyle (2012) on computer games and SG. Many academic search engines were scanned within the scope of this study. In addition, many keywords were used during the scans (e.g.: computer games, video games, serious games, simulation games, games-based learning, MMOG etc.). Of the 7392 records obtained, 129 were selected for inclusion in the study. Studies were carried out under headlines such as "Study design used in papers", Game variables (Digital/non-digital, Game genre, Platform/delivery, etc.), outcomes and impacts of playing games. The acquired results and findings were included under the related headlines as a result of the studies. This study was published in the prestigious Journal of Computers \& Education and has received 590 citations as of November 2017.

Connolly et.al. (2012) expanded the study group and carried out an updated version of the same study. As a result of this study, it was emphasized that developing games is a complex, expensive area with certain difficulties despite that fact that GBL and SG attract significant attention.

Petri and Gresse von Wangenheim (2017) carried out a study in which they examined 112 studies from among a total of 3617. The study was structured under the titles of research questions, study types/research designs, evaluation models/methods, data collection instruments and sample sizes. Backlund and Hendrix (2013) analyzed 40 studies of the effectiveness of educational games including only four on computing education. Calderón and Ruiz (2015) identified common methods, categories, features, procedures, and size populations in the assessment of SG. In addition, many literature review studies have been carried out that are similar to the areas of SG or GBL (e.g.: Calderón \& Ruiz, 2015; Petri \& Gresse von Wangenheim, 2017, etc.)

Bibliometric methods are based on the examination of the bibliometric data in scientific publications such as citations by way of mathematical and statistical methods (Özçınar, 2017). Bibliometric analysis is a method that is used for summarizing the studies in literature by measuring certain indicators (Thelwall, 2008). According to Chen (2017), "Science mapping is a generic process of domain analysis and visualization". Numeric statistics related to the increase in publications over the years along with the listing of those who have contributed the most (authors, institutions, countries etc.), cooperation between authors/institutions, percentage of references per publication can be carried out via bibliometric methods. The fundamental assumption of bibliometric analysis methods is that citations are indicators of the impact of the cited publication (Culnan, 1986). Drawing out quantitative meanings from large sets of data is the objective of this analysis method. The objective is to enrich past and future analyses and their proper guidance in addition to the presentation of numerical data.

Today, certain opinions have emerged regarding the possibility of making meaningful inferences by examining the data which can be stored in detail in advanced databases. Concepts such as big data, data mining, bibliometric analysis, log data analysis can be indicated as the products of such ideas. Different tools have been developed for bibliometric analyses. It can be stated that Bibexcel, Publish or Perish, Pajek, CiteSpace, SciMat, Sci2, VOSviewer are the most frequently used among these. The majority of these softwares have been developed by academics or by an academic project group without seeking any profit. Web of Science, Scopus, Google Scholar and PubMed are among the most popular databases for this data analysis method. The reasons for selecting these are the ability to store detailed data and the ability to present these data to researchers in an easily accessible manner.

This study seeks to answer the following questions by taking into consideration the number of citations and common citation numbers in publications that have been published in indexed journals between 2007 and2017:

1. How does the quantitative distribution change depending on the years and types of publication?

2. How is the quantitative distribution with regard to;

a. countries and university institution,

b. source titles,

c. research areas,

d. prolific authors and publications,

e. words.

\section{Method}

\subsection{Data Collection}

The aim of this study was to investigate papers about serious games. The study was designed as a descriptive research because it mainly tended to discover current status of serious games researches covering Web of Science articles. For 
this purpose, a bibliometric analysis method was used in the study. With the help of bibliometric analysis method; it is possible to identify trends, prolific authors, prolific journals and most cited articles to get a clear idea about future. Additionally, using bibliometric analysis software tools make it possible to domain analysis and visualization.

Web of Science (WOS) was selected as the data collection source within the scope of this study. The primary reason for selecting this data source was the inclusion of detailed records of the publications scanned in SCI-EXPANDED, SSCI and A\&HCI indexes. The second reason was the easy and organized access to data required for bibliometric analyses via WOS database as mentioned by Okubo (1997).

In order to collect the data of the study, some specific steps were followed. Firstly, WOS search engine was used for scanning the "serious game" keyword in the title, keywords and abstract sections for acquiring data. Then, the results were filtered to cover the years 2007-2017. For this process, no limitation was made on the type of study. So, a total of 1431 publications could be reached. After this step, the accessed data were saved as separated tab text formats.

Several biometric analysis tools have been analyzed by the researcher. It is possible to do similar analyzes with various bibliometric analysis software. However, CiteSpace and VOSviewer were selected for this study as these data analysis tools are generally accepted as the wide-used tools in the field (Chen, 2017). Following this way, according to the WOS analysis results, the total number of citations was determined as 12701 , average number of citations per publication was determined as 8.88 , whereas h-index was determined as 51 .

\subsection{Data Analysis}

Data such as the country, institution and time distribution of the relevant studies were acquired from the WOS database. CiteSpace and VOSviewer software tools were used for bibliometric analyses. CiteSpace software was developed by Chen (2004) and is widely used for the mapping of the development of scientific areas ( Liu, Jiang, \& Jin, 2014). VOSviewer is a software tool for constructing and visualizing bibliometric networks that was developed by the "Centre for Science and Technology Studies, Leiden University". By using the tools, distribution according to years and type of publication, publication time and type trends, prolific countries and universities, prolific research areas was investigated.

\section{Results}

The results of the analysis were tabulated and transformed into graphs via 3 different methods. The first of these methods included acquiring the results from using the "analysis results" and "Create Citation Report" sections that appear on the screen following a query on the WOS web page. Other findings were determined as a result of analyzing the ".txt" format data obtained from WOS database via VOSviewer and CiteSpace software. The related findings have been presented and interpreted under the Results heading.
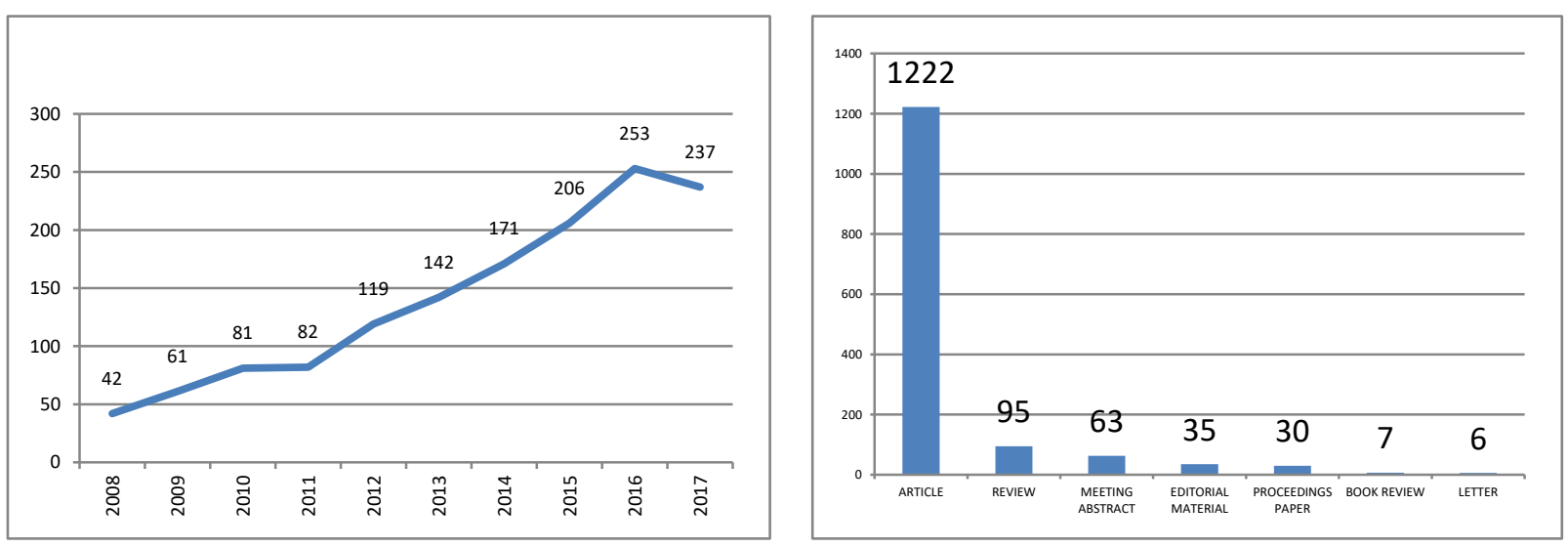

Figure 1. Distribution according to years and type of publication

\subsection{Publication Time and Type Trends}

It can be observed from Figure 1 that when the distribution of SG according to the years of publications is examined there is an increase starting from the year 2008. This figure also shows a decline in the number of studies after 2016., However, it should be taken into consideration that this study concluded in October 2017 and therefore it would not be correct as of yet to state that there is a decrease in the trend in 2017. When the distribution according to type displayed in Figure 1 is considered, the maximum value $(\mathrm{n}=1222)$ was for the publications of "Article" type. Review, meeting abstract, editorial material and proceeding paper varied between $n=30$ and $n=95$. 


\subsection{Prolific Countries and Universities}

It can be observed from an examination of Table 1 that the highest number of publications on SG has been carried out by the USA (28\%). The following countries were the United Kingdom (10\%) and Holland (10\%). English was determined as the language that was used the most with a ratio of $9 \%$ when the publication languages were considered. French was ranked second with $1.67 \%$. The percentages of the remaining languages were all below $1 \%$.

Table 1. Distribution of publications according to countries

\begin{tabular}{lrr}
\hline Countries/Territories & Record Count & \% of 1431 \\
\hline USA & 401 & $28 \%$ \\
\hline United Kingdom & 147 & $10 \%$ \\
\hline Netherlands & 145 & $10 \%$ \\
\hline Spain & 118 & $8 \%$ \\
\hline France & 96 & $6 \%$ \\
\hline China & 96 & $6 \%$ \\
\hline Germany & 72 & $5 \%$ \\
\hline Canada & 68 & $4 \%$ \\
\hline Italy & 68 & $4 \%$ \\
\hline Australia & 63 & $4 \%$ \\
\hline Other Countries & 157 & $15 \%$
\end{tabular}

It was observed that when the universities making the highest number of publications were examined that Delft University of Technology $(n=21)$, Amsterdam University $(n=20)$ and Utrecht Univ. $(n=20)$ were in the top three. The next ranked universities were: Coventry Univ. $(n=18)$, Vrije Universiteit Amsterdam $(n=17)$, Maastricht Univ. $(n=15)$, University of Twente ( $\mathrm{n}=15)$, Harvard Univ. ( $\mathrm{n}=14)$, Stanford Univ. $(\mathrm{n}=14)$ and Ghent Univ. ( $\mathrm{n}=14)$ respectively.

\subsection{Prolific Source Titles}

There were a total of 782 different journals or symposiums in the data set. Computers Education ( $\mathrm{n}=58)$, Computers in Human Behavior $(n=45)$ and Games for Health Journal $(n=41)$ attract attention as the sources that make the highest number of publications in the data set. The number of records of the sources making the highest number of publications may seem low. However, the interpretation of the number of publications can be seen more clearly when it is considered that there are 782 different sources. The 10 sources with the highest number of SG related publications are presented in Table 2 .

Table 2. Distribution of publications according to Source Titles

\begin{tabular}{lr}
\hline Source Titles & Record Count \\
\hline Computers Education & 58 \\
\hline Computers in Human Behavior & 45 \\
\hline Games for Health Journal & 41 \\
\hline British Journal of Educational Technology & 24 \\
\hline Games and Culture & 17 \\
\hline Multimedia Tools and Applications & 17 \\
\hline Journal of Medical Internet Research & 16 \\
\hline Plos One & 15 \\
\hline Frontiers in Psychology & 14 \\
\hline Visual Computer & 12 \\
\hline
\end{tabular}

\subsection{Prolific Research Areas}

When the number of publications according to the publication areas listed in Table 3 is taken into consideration, the 
number of studies on SG from different disciplines attracts attention. Studies carried out in fields of Psychology, Health Care Sciences Services, Environmental Sciences Ecology, Public Environmental Occupational Health, Rehabilitation, Business Economics and Psychiatry indicate that SG is being used in the teaching of different disciplines.

Table 3. Distribution of publications according to Research Areas

\begin{tabular}{lrr}
\hline \multicolumn{1}{c}{ Research Areas } & Record Count & \% of 1431 \\
\hline Computer Science & 302 & $21.10 \%$ \\
\hline Education - Educational Research & 204 & $14.25 \%$ \\
\hline Psychology & 171 & $11.95 \%$ \\
\hline Engineering & 155 & $10.83 \%$ \\
\hline Health Care Sciences Services & 87 & $6.08 \%$ \\
\hline Environmental Sciences Ecology & 79 & $5.52 \%$ \\
\hline Public Environmental Occupational Health & 76 & $5.31 \%$ \\
\hline Rehabilitation & 69 & $4.82 \%$ \\
\hline Business Economics & 61 & $4.26 \%$ \\
\hline Psychiatry & 57 & $3.98 \%$ \\
\hline
\end{tabular}

\subsection{Prolific Authors}

When the number of publications according to the authors in Table 4 are taken into consideration, it can be observed that Baranowski $(n=11)$, Robert $(n=10)$ and Thompson $(n=10)$ are the authors with the highest number of publications on SG. A list of 10 authors with the highest number of publications is given in Table 4.

Table 4. Distribution of publications according to authors

\begin{tabular}{lr}
\hline Authors & Record Count \\
\hline Baranowski T & 11 \\
\hline Robert P & 10 \\
\hline Thompson D & 10 \\
\hline Van Oostendorp H & 9 \\
\hline Bellotti F & 8 \\
\hline Buday R & 8 \\
\hline Fernandez-Manjon B & 8 \\
\hline Torrente J & 8 \\
\hline Wouters P & 8 \\
\hline Kim J & 7
\end{tabular}

The diameters of the knots symbolizing the publications in the common citation network representations are put forth in direct proportion with the number of citations that publication has received (Özçınar, 2017). It can be observed when Figure 2 is examined that Connolly et.al. (2012), Saposnik (2010), Gunter (2008) and Graafland (2012) are among the examples of publications that received the highest number of citations as a result of the common citation analysis. The centrality of a node within the network of nodes or its closeness indicates its strategic importance in the publication network. 


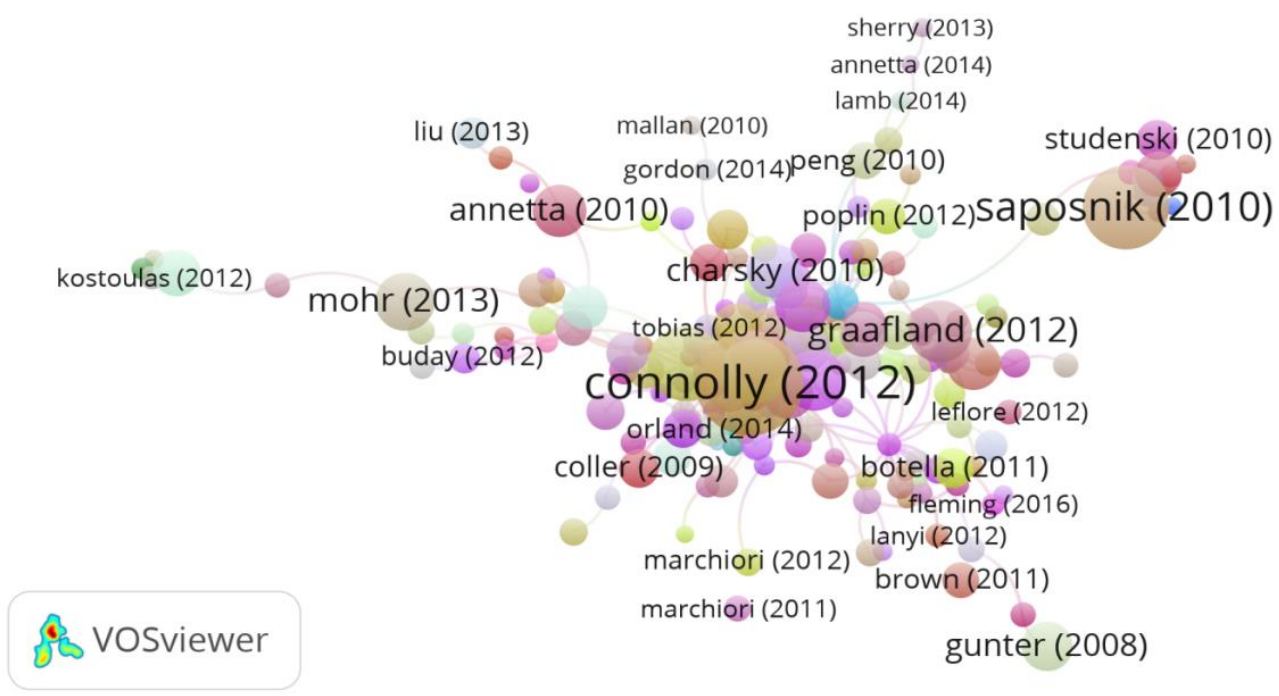

Figure 2. Author based common citation analysis concept map

Table 5. Ten publications that received the highest number of citations

\begin{tabular}{|c|c|c|c|c|c|}
\hline Title & Authors & Source Title & $\begin{array}{l}\text { Pub. } \\
\text { Year }\end{array}$ & $\begin{array}{l}\text { Total } \\
\text { Citations }\end{array}$ & $\begin{array}{l}\text { Average } \\
\text { per Year }\end{array}$ \\
\hline $\begin{array}{l}\text { A systematic literature review of } \\
\text { empirical evidence on computer games } \\
\text { and serious games }\end{array}$ & $\begin{array}{l}\text { Connolly, Thomas M.; Boyle, Elizabeth } \\
\text { A.; MacArthur, Ewan; Hainey, Thomas; } \\
\text { Boyle, James M. }\end{array}$ & $\begin{array}{l}\text { Computers \& } \\
\text { Education }\end{array}$ & 2012 & 448 & 74,67 \\
\hline $\begin{array}{l}\text { Effectiveness of Virtual Reality Using } \\
\text { Wii Gaming Technology in Stroke } \\
\text { Rehabilitation A Pilot Randomized } \\
\text { Clinical Trial and Proof of Principle }\end{array}$ & $\begin{array}{l}\text { Saposnik, Gustavo; Teasell, Robert; } \\
\text { Mamdani, Muhammad; Hall, Judith; } \\
\text { McIlroy, William; Cheung, Donna; } \\
\text { Thorpe, Kevin E.; Cohen, Leonardo G.; } \\
\text { Bayley, Mark }\end{array}$ & Stroke & 2010 & 258 & 32,25 \\
\hline $\begin{array}{l}\text { Weight-bearing exercise and bone } \\
\text { mineral accrual in children and } \\
\text { adolescents: A review of controlled } \\
\text { trials }\end{array}$ & Hind, K.; Burrows, M. & Bone & 2007 & 225 & 20,45 \\
\hline $\begin{array}{l}\text { A Meta-Analysis of the Cognitive and } \\
\text { Motivational Effects of Serious Games }\end{array}$ & $\begin{array}{l}\text { Wouters, Pieter; van Nimwegen, } \\
\text { Christof; van Oostendorp, Herre; van } \\
\text { der Spek, Erik D. }\end{array}$ & $\begin{array}{l}\text { Journal Of } \\
\text { Educational } \\
\text { Psychology }\end{array}$ & 2013 & 192 & 38,4 \\
\hline $\begin{array}{l}\text { Entrepreneurship Education: Known } \\
\text { Worlds and New Frontiers }\end{array}$ & Neck, Heidi M.; Greene, Patricia G. & $\begin{array}{l}\text { Journal Of Small } \\
\text { Business } \\
\text { Management }\end{array}$ & 2011 & 165 & 23,57 \\
\hline $\begin{array}{l}\text { Optimising engagement for stroke } \\
\text { rehabilitation using serious games }\end{array}$ & $\begin{array}{l}\text { Burke, J. W.; McNeill, M. D. J.; } \\
\text { Charles, D. K.; Morrow, P. J.; Crosbie, } \\
\text { J. H.; McDonough, S. M. }\end{array}$ & Visual Computer & 2009 & 155 & 17,22 \\
\hline $\begin{array}{l}\text { Our Princess Is in Another Castle: A } \\
\text { Review of Trends in Serious Gaming } \\
\text { for Education }\end{array}$ & $\begin{array}{l}\text { Young, Michael F.; Slota, Stephen; } \\
\text { Cutter, Andrew B.; Jalette, Gerard; } \\
\text { Mullin, Greg; Lai, Benedict; Simeoni, } \\
\text { Zeus; Tran, Matthew; Yukhymenko, } \\
\text { Mariya }\end{array}$ & $\begin{array}{l}\text { Review of } \\
\text { Educational } \\
\text { Research }\end{array}$ & 2012 & 136 & 22,67 \\
\hline $\begin{array}{l}\text { Systematic review of serious games } \\
\text { for medical education and surgical } \\
\text { skills training }\end{array}$ & $\begin{array}{l}\text { Graafland, M.; Schraagen, J. M.; } \\
\text { Schijven, M. P. }\end{array}$ & $\begin{array}{l}\text { British Journal of } \\
\text { Surgery }\end{array}$ & 2012 & 121 & 20,17 \\
\hline $\begin{array}{l}\text { Computerized Cognitive Training } \\
\text { Restores Neural Activity within the } \\
\text { Reality Monitoring Network in } \\
\text { Schizophrenia }\end{array}$ & $\begin{array}{l}\text { Subramaniam, Karuna; Luks, Tracy L.; } \\
\text { Fisher, Melissa; Simpson, Gregory V.; } \\
\text { Nagarajan, Srikantan; Vinogradov, } \\
\text { Sophia }\end{array}$ & Neuron & 2012 & 116 & 19,33 \\
\hline $\begin{array}{l}\text { Not just fun, but serious strategies: } \\
\text { Using meta-cognitive strategies in } \\
\text { game-based learning }\end{array}$ & $\begin{array}{l}\text { Kim, Bokyeong; Park, Hyungsung; } \\
\text { Baek, Youngkyun }\end{array}$ & $\begin{array}{l}\text { Computers \& } \\
\text { Education }\end{array}$ & 2009 & 116 & 12,89 \\
\hline
\end{tabular}

The publication that received the highest number of citations was the study by Connolly et.al. (2012) published in the 
Computers \& Education Journal in which a literature review was made on computer games and SG. Saposnik et.al. (2010) carried out a study which was published in the "Stroke" Journal. This publication received a total of 258 citations and the average number of citations per year can be seen as 32.25 . When the data in Table 5 are considered, it can be stated that there was a boom in citations between 2010 and 2012. In addition, the keywords of "Stroke Rehabilitation, Clinical Trial, Medical Education, Neural Activity, Schizophrenia" indicate that SG has been studied in disciplines other than education technology and that it is a popular topic of study.

Word trends

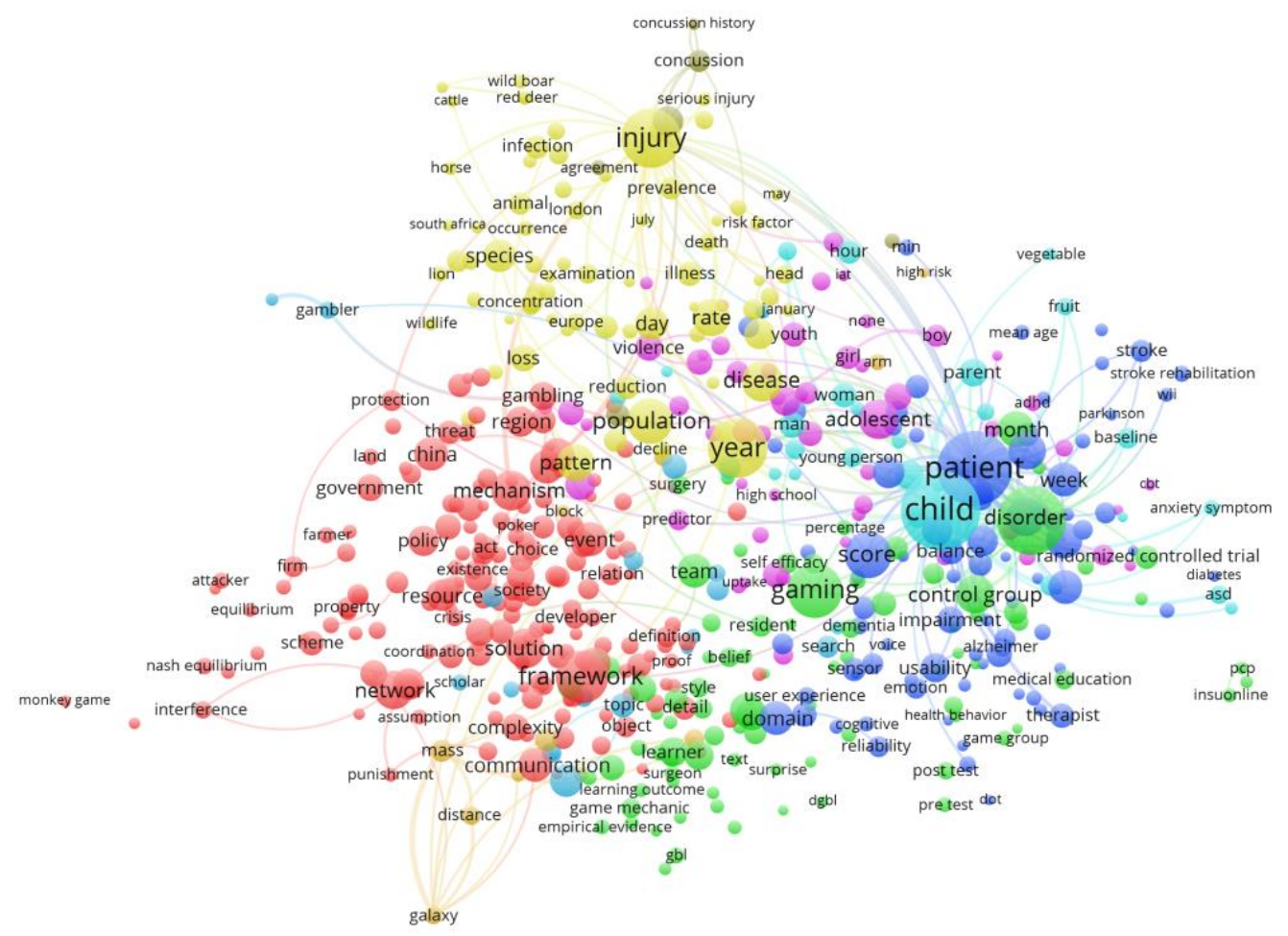

Figure 3. Common citation analysis concept map according to word basis

This figure shows the visual map via VOSviewer for the common citation analysis according to years. According to this map, common colors represent close subjects/disciplines whereas the connecting lines represent the citation relations/paths. The blue nodes on the map (patient, score, therapist, alzheimer, domain etc.) mostly encompass studies in fields such as Health, Medicine, Medical. Studies with the same or similar "research areas" have been classified under the same color. A total of 176 items and 9 clusters emerged as a result of the analysis. 


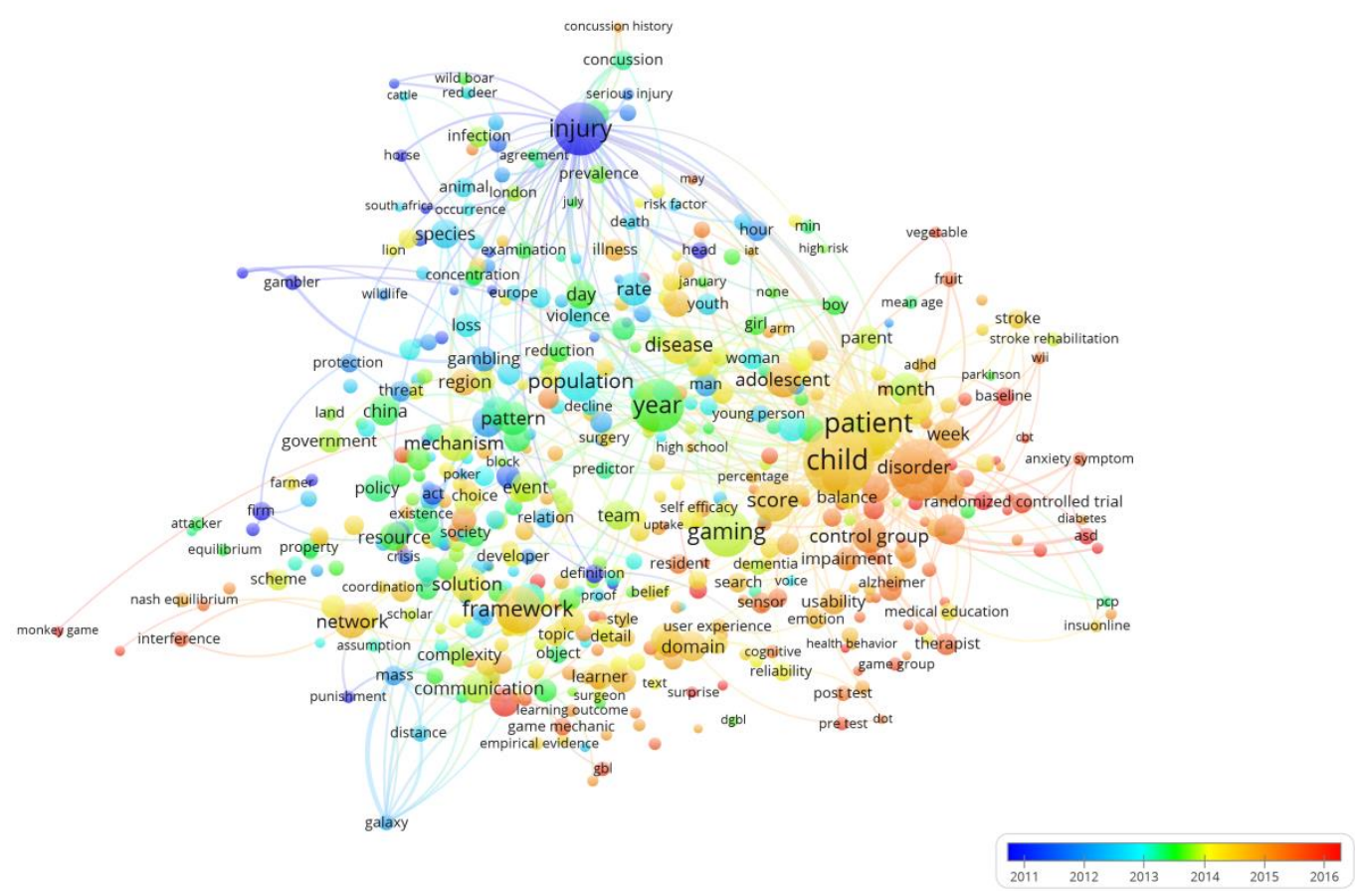

Figure 4. Common citation analysis concept map on word basis according to the years

Figure 4 shows the distribution by year of the concept map generated according to common citations. The publication dates of the concepts become less recent as the color approaches blue whereas yellow - orange nodes indicate the publications and citations generated more recently.

\section{Conclusions}

The findings of this study provide information regarding the years, type of publication, countries, institutions, study areas, frequently used words, trend/most cited authors and publications for studies carried out in the field of SG. Examination of the currently completed studies by way of text mining and bibliometric analysis methods yield useful results. Findings related to the tendencies of the field and the authors can be evaluated in detail using these methods. Structured data provided by academic search engines along with software such as VOSviewer and CiteSpace are of great use for the acquisition and analysis of these results. It is not required to direct the developments in the field of SG by analyzing the current trends. However, trend analysis results will be beneficial for the field of SG. They might especially be useful to individuals who wish to carry out studies in this field for finding a starting point.

According to the results obtained from this study, an increase in SG related publications was observed. It can be seen that the increase of publications stopped for a brief period of time during the years of 2010 and 2011 and that the graph curve continued as a constant. However, it was observed that the increase in the number of publications continued in 2012. It can be stated that publications with frequent citations and leading publications have an important impact on the change of this horizontal course (Connolly et.al., 2012). Similar to the current study results, Hwang and Wu (2012) carried out a trend analysis study in which it was stated that there was an increase in the number of studies on GBL during the 2006-2010 interval.

When the SG publications according to countries are considered, it can be observed that the USA is a leader in this field with significant contributions. The United Kingdom and Holland were ranked after the USA. The most frequently used publication language was English. Results on the journals with the highest number of publications, the publication language of these journals and their respective countries all overlap with each other.

Examination of the study areas yielded an interesting result. It was observed that a significant number of publications have been made on SG in other fields while it was the leading topic in the field of education technology. The areas of Psychology, Health Care Sciences Services, Environmental Sciences, Ecology, Public Environmental Occupational Health, Rehabilitation, Business Economics and Psychiatry can be given as examples. It can be stated that the use of SG in the education of another discipline is a good development. It is an indication that innovations based on technology are not studied only in the area of technology and that they are studied in other areas as well and that the concept of SG has also been accepted and popularized in other areas. 
When the author with the highest citations was examined by way of common citation analysis, it was observed that the publications during the years of 2010-2012 (e.g.:Charsky, 2010; Connolly et.al., 2012; Graafland, Schraagen, \& Schijven, 2012) come to the forefront. It can be seen from 2013-2014 (e.g.:Annetta et.al., 2014; D. Liu, Li, \& Santhanam, 2013) and 2016 (e.g.:(Fleming et.al., 2016)) that the leading authors also started to come to the forefront with regard to receiving citations. In addition, it can be observed according to the common citation analysis results that some of the publications which received a significant number of citations are trend analyses based on literature reviews. This is an indication of the importance of trend analysis studies and the interest they receive in the literature.

Analyses on the most frequently used words in the studies also provide information on the terminology of the study areas. In addition, these analysis results overlap with the study results related to the study areas. It was observed that the words in publications that receive common citation are related to each other and grouped according to areas.

It is significant that studies on SG attract the attention of the developers in the field as well as researchers in different disciplines. According to these results, it can be stated that the field of SG is an effective method for learning and that it continues to attract attention. Publications in prestigious journals along with common citation analyses provide detailed results regarding this interest and tendency. The study area can be examined from many different perspectives especially by way of bibliometric studies. It is also beneficial that bibliometric tools combine different parameters in different manners thus enabling the researchers to carry out rich analyses.

\section{References}

Abt, C. C. (1970). Serious games: The art and science of games that simulate life. New Yorks Viking, 6.

Annetta, L., Lamb, R., Minogue, J., Folta, E., Holmes, S., Vallett, D., \& Cheng, R. (2014). Safe science classrooms: Teacher training through serious educational games. Information Sciences, 264, 61-74.

Boyle, E. A., Hainey, T., Connolly, T. M., Gray, G., Earp, J., Ott, M., ... Pereira, J. (2016). An update to the systematic literature review of empirical evidence of the impacts and outcomes of computer games and serious games. Computers \& Education, 94(Supplement C), 178-192. https://doi.org/https://doi.org/10.1016/j.compedu.2015.11.003

Calderón, A., \& Ruiz, M. (2015). A systematic literature review on serious games evaluation: An application to software project management. Computers \& Education, 87(Supplement C), 396-422. https://doi.org/10.1016/j.compedu.2015.07.011

Charsky, D. (2010). From edutainment to serious games: A change in the use of game characteristics. Games and culture, 5(2), 177-198.

Chen, C. (2004). Searching for intellectual turning points: Progressive knowledge domain visualization. Proceedings of the National Academy of Sciences of the United States of America, 101, 5303-5310. https://doi.org/10.1073/pnas.0307513100

Chen, C. (2017). Science Mapping: A Systematic Review of the Literature. Journal of Data and Information Science, 2 , 1-40. https://doi.org/10.1515/jdis-2017-0006

Clark, C. A. (1970). Serious games. New York: Viking Press.

Connolly, T. M., Boyle, E. A., MacArthur, E., Hainey, T., \& Boyle, J. M. (2012). A systematic literature review of empirical evidence on computer games and serious games. Computers \& Education, 59(2), 661-686. https://doi.org/https://doi.org/10.1016/j.compedu.2012.03.004

Corti, K. (2006). Games Based Learning. A Serious Business Application, PIXELearning, 20.

Culnan, M. J. (1986). The intellectual development of management information systems, 1972-1982: A co-citation analysis. Management science, 32(2), 156-172.

Ebner, M., \& Holzinger, A. (2007). Successful implementation of user-centered game based learning in higher education: An example from civil engineering. Computers \& education, 49(3), 873-890.

Egenfeldt-Nielsen, S. (2011). Beyond edutainment: Exploring the educational potential of computer games. Lulu. com.

Fleming, T. M., De Beurs, D., Khazaal, Y., Gaggioli, A., Riva, G., Botella, C., ... Kleiboer, A. (2016). Maximizing the impact of e-therapy and serious gaming: time for a paradigm shift. Frontiers in psychiatry, 7.

Graafland, M., Schraagen, J. M., \& Schijven, M. P. (2012). Systematic review of serious games for medical education and surgical skills training. British journal of surgery, 99(10), 1322-1330.

Greitzer, F. L., Kuchar, O. A., \& Huston, K. (2007). Cognitive science implications for enhancing training effectiveness in a serious gaming context. Journal on Educational Resources in Computing (JERIC), 7(3), 2. 
Hakulinen, L. (2011). Using serious games in computer science education. Içinde Proceedings of the 11th Koli Calling International Conference on Computing Education Research (ss. 83-88). ACM.

Hwang, G. J., \& Wu, P. H. (2012). Advancements and trends in digital game-based learning research: a review of publications in selected journals from 2001 to 2010. British Journal of Educational Technology, 43(1), E6-E10. https://doi.org/10.1111/j.1467-8535.2011.01242.x

Johnson, S. (2006). Everything bad is good for you: How today's popular culture is actually making us smarter. Penguin.

Kirriemuir, J., \& McFarlane, A. (2004). Literature review in games and learning.

Lee, K. M., \& Peng, W. (2006). What do we know about social and psychological effects of computer games? A Comprehensive review of the current literature. https://doi.org/10.4324/9780203873700

Liu, D., Li, X., \& Santhanam, R. (2013). Digital Games and Beyond: What Happens When Players Compete. Mis Quarterly, 37(1).

Liu, G., Jiang, R., \& Jin, Y. (2014). Sciatic nerve injury repair: a visualized analysis of research fronts and development trends. Neural Regeneration Research, 9(18), 1716-1722. https://doi.org/10.4103/1673-5374.141810

McFarlane, A., Sparrowhawk, A., \& Heald, Y. (2002). Report on the educational use of games. TEEM (Teachers evaluating educational multimedia), Cambridge.

McGonigal, J. (2011). Reality is broken: Why games make us better and how they can change the world. Penguin.

Özçınar, H. (2017). Hesaplamali Düşünme Araştirmalarinin Bibliyometrik Analizi. Eğitim Teknolojisi Kuram ve Uygulama, 7(2), 149-171. https://doi.org/10.17943/etku.288610

Petri, G., \& Gresse von Wangenheim, C. (2017). How games for computing education are evaluated? A systematic $\begin{array}{lllll}\text { literature review. Computers \& Education, } 107 \text { (Supplement } & \text { C), }\end{array}$ https://doi.org/10.1016/j.compedu.2017.01.004

Robertson, J., \& Howells, C. (2008). Computer game design: Opportunities for successful learning. Computers \& Education, 50(2), 559-578.

Saposnik, G., Teasell, R., Mamdani, M., Hall, J., Mcllroy, W., Cheung, D., ... Stroke Outcome Research Canada (SORCan) Working Group. (2010). Effectiveness of virtual reality using Wii gaming technology in stroke rehabilitation: a pilot randomized clinical trial and proof of principle. Stroke, 41(7), 1477-1484. https://doi.org/10.1161/STROKEAHA.110.584979

Sawyer, B., \& Smith, P. (2008). Serious games taxonomy. Içinde Slides from the Serious Games Summit at the Game Developers Conference.

Stokes, B. (2012). Restructuring civic engagement: Meaningful choice and game design thinking. The Participatory Cultures Handbook, 143-152.

Taylor, M., Harlow, A., \& Forret, M. (2010). Using a Computer Programming Environment and an Interactive Whiteboard to Investigate Some Mathematical Thinking. Procedia-Social and Behavioral Sciences, 8(Supplement C), 561-570. https://doi.org/10.1016/j.sbspro.2010.12.078

Thelwall, M. (2008). Bibliometrics to webometrics. Journal of information science, 34(4), 605-621.

\section{Copyrights}

Copyright for this article is retained by the author(s), with first publication rights granted to the journal.

This is an open-access article distributed under the terms and conditions of the Creative Commons Attribution license which permits unrestricted use, distribution, and reproduction in any medium, provided the original work is properly cited. 